Editorial

\title{
Risk factors for age-related cataract
}

\author{
Stuart Keel ${ }^{1}$ and Mingguang He PhD FRANZCO ${ }^{1,2}$
}

1. Centre for Eye Research Australia, University of Melbourne, Melbourne, Australia

2. State Key Laboratory of Ophthalmology, Zhongshan Ophthalmic Center, Sun Yatsen University, Guangzhou, China

Conflict of interest: None

Funding sources: None

Correspondence: Mingguang He, Zhongshan Ophthalmic Center, Guangzhou, People's Republic of China; University of Melbourne, Australia

Email: mingguang he@yahoo.com

This is the author manuscript accepted for publication and has undergone full peer review but has not been through the copyediting, typesetting, pagination and proofreading process, which may lead to differences between this version and the Version of Record. Please cite this article as doi: $10.1111 /$ ceo.13309

This article is protected by copyright. All rights reserved. 
Cataract is a leading cause of treatable vision loss globally. ${ }^{1}$ Given the considerable burden of cataract, and its feasibility of treatment, it is not surprising that cataract surgery is the most common elective surgical procedure performed in the world. Despite this, many people, particularly those in developing nations, remain blind from cataract due an inadequate availability of surgery services or high surgical expenses. With an aging global population, a significant increase in the demand for cataract surgery and related economic burden is projected. Thus, from a public health perspective, identifying modifiable risk factors of cataract may be useful to improve awareness and to help establish practical preventive measures.

Internationally, several population-based studies have investigated risk factors associated with cataract. ${ }^{2-5}$ However these data have mainly been derived from Western populations, and to date, there is a paucity of population-based data from Asian countries, including China. ${ }^{6}$ With this in mind, Tang et $\mathrm{al}^{7}$ conducted a population-based study, the Taizhou Eye Study, that investigated risk factors for age-related cataract and its sub-types amongst Chinese adults aged 45 years or older. Participation rates were robust $(78.1 \%)$, making generalisability of their outcomes favourable for the target population, and the investigators should also be commended for the inclusion of a large sample size $(n=>10,000)$, capturing a comprehensive range of known and potential cataract-related risk factors, and the use of a standardized protocol to grade for cataract (LOCS III). The authors report that age, female gender, longer outdoor activity, lack of outdoor eye protection, high myopia, a poorer lipid profile (low high-density lipoproteins and high low-density lipoproteins) and pickled food intake were independent risk factors for any cataract. Some variation among associations with cataract sub-types were also exhibited lower daily herbal intake was associated with nuclear cataract; lower family income was related to cortical cataract; and higher diastolic blood pressure was associated with posterior sub-capsular cataract. The authors concluded that improved awareness and adequate control of the identified modifiable risk factors may help 
reduce the risk of age-related cataract development amongst the Chinese population.

It is clear from the substantial amounts of epidemiological data on this topic that age-related cataract is a multifactorial disease, and different risk factors appear to play a role in different cataract sub-types. Non-modifiable (advanced age and female gender) and socio-economic risk factors (fewer years of education, lower family income) reported by Tang and colleagues are consistent with the large body of previous literature. However, modifiable risk factors (biological or lifestyle factors) that may increase the prevalence of age-related cataract are of particular interest as they are potentially amenable to interventions targeting their reduction. Although not reported by Tang et al, diabetes, ${ }^{8}$ smoking $^{9}$ and cortico-steroid use ${ }^{10}$ are perhaps three of the most well-recognised modifiable risk factors for age-related cataract. While it is plausible that these associations are influenced by ethnic categorisation, the negative results in the Teng et al. report could also be attributable to other confounding factors. For example, a failure to capture details on the quantity of smoking consumption is likely to have led to bias. Much of the current evidence, including that from Tang et al, also supports the role of chronic sunlight exposure, in particular ultraviolet (UV)-B, on the development of age-related cataracts.

The research by Tang and colleagues also raises some interesting associations that are particularly pertinent to the local circumstances in China. Firstly, in line with the Beijing Eye Study baseline examination, ${ }^{6}$ the authors finding that myopia was an independent risk factor for age-related cataract is of particular interest given the high and increasing burden of myopia in China. However, due to the cross-sectional nature of this study, it is difficult to determine whether the myopia-cataract association is entirely related to the effect of pre-existing myopia on the development of cataract, or whether this association is related to the myopia simply being induced by nuclear sclerosis. Findings from population-based 
longitudinal studies on the association between myopia and cataract have been mixed. ${ }^{11,12}$ Given the lens is particularly sensitive to nutrient deficiencies, numerous studies have been conducted to investigate the relationship between diet and risk of cataract in older people. However, these studies have produced conflicting findings. A 2012 Cochrane review concluded that there is no evidence that specific antioxidants of vitamin $\mathrm{E}$, vitamin $\mathrm{C}$ or beta-carotene prevent or slow the progression of age-related cataract. ${ }^{13}$ Nonetheless, the relatively novel finding by Tang et al. of an association between pickled food intake and increased risk of cataract is of interest, given that pickled food (particularly pickled vegetables) constitute an important part of the family diet in many parts of China. Additional data would be required to elucidate the mechanistic hypotheses for this finding.

In conclusion, Tang et al. should be congratulated for their work that sheds some light on the associations of age-related cataract in a Chinese population, where evidence has previously been scarce. Given the few well-established modifiable cataract-related risk factors identified by Tang et al. and other crosssectional, case-control and prospective studies (UV-B exposure, smoking, diabetes) are also associated with other adverse health outcomes, interventions aimed at improving their control should be promoted. However, it remains that additional longitudinal and/or interventional data examining the interactive role of other potentially modifiable factors, such as diet, are required to help elucidate additional practical steps to move forward for cataract risk reduction. 


\section{REFERENCES}

1. Flaxman SR, Bourne RRA, Resnikoff $S$, et al. Global causes of blindness and distance vision impairment 1990-2020: a systematic review and meta-analysis. The Lancet Global health 2017; 5(12): e1221-e34.

2. Klein $B E$, Klein RE, Lee KE. Incident cataract after a five-year interval and lifestyle factors: the Beaver Dam eye study. Ophthalmic Epidemio/1999; 6(4): 24755.

3. Navarro Esteban JJ, Gutierrez Leiva JA, Valero Caracena N, Buendia Bermejo J, Calle Puron ME, Martinez Vizcaino VJ. Prevalence and risk factors of lens opacities in the elderly in Cuenca, Spain. European journal of ophthalmology 2007; 17(1): 2937.

4. Richter GM, Choudhury F, Torres M, Azen SP, Varma R. Risk factors for incident cortical, nuclear, posterior subcapsular, and mixed lens opacities: the Los Angeles Latino eye study. Ophthalmology 2012; 119(10): 2040-7.

5. Tan JS, Wang JJ, Younan C, Cumming RG, Rochtchina E, Mitchell P. Smoking and the long-term incidence of cataract: the Blue Mountains Eye Study. Ophthalmic Epidemio/2008; 15(3): 155-61.

6. Xu L, Cui T, Zhang S, et al. Prevalence and risk factors of lens opacities in urban and rural Chinese in Beijing. Ophthalmology 2006; 113(5): 747-55.

7. Tang $Y$, Wang $X$, Wang J, et al. Risk factors of age-related cataract in a Chinese adult population: the Taizhou Eye Study. Clinical \& experimental ophthalmology 2017.

8. Pollreisz A, Schmidt-Erfurth U. Diabetic cataract-pathogenesis, epidemiology and treatment. Journal of ophthalmology 2010; 2010: 608751.

9. Kelly SP, Thornton J, Edwards R, Sahu A, Harrison R. Smoking and cataract: review of causal association. Journal of cataract and refractive surgery 2005; 31(12): 2395-404. 
10. James ER. The etiology of steroid cataract. Journal of ocular pharmacology and therapeutics : the official journal of the Association for Ocular Pharmacology and Therapeutics 2007; 23(5): 403-20.

11. Kanthan GL, Mitchell P, Rochtchina E, Cumming RG, Wang JJ. Myopia and the long-term incidence of cataract and cataract surgery: the Blue Mountains Eye Study. Clinical \& experimental ophthalmology 2014; 42(4): 347-53.

12. Zhang JS, Xu L, Wang YX, You QS, Wang JD, Jonas JB. Five-year incidence of age-related cataract and cataract surgery in the adult population of greater Beijing: the Beijing Eye Study. Ophthalmology 2011; 118(4): 711-8.

13. Mathew MC, Ervin AM, Tao J, Davis RM. Antioxidant vitamin supplementation for preventing and slowing the progression of age-related cataract. The Cochrane database of systematic reviews 2012; (6): Cd004567.

14. Wei L, Liang G, Cai C, Lv J. Association of vitamin C with the risk of agerelated cataract: a meta-analysis. Acta Ophthalmo/ 2016; 94(3): e170-6. 


\section{University Library}

\section{- M M I E E R VA A gateway to Melbourne's research publications}

Minerva Access is the Institutional Repository of The University of Melbourne

Author/s:

Keel, S;He, M

Title:

Risk factors for age-related cataract

Date:

2018-05-01

Citation:

Keel, S. \& He, M. (2018). Risk factors for age-related cataract. CLINICAL AND

EXPERIMENTAL OPHTHALMOLOGY, 46 (4), pp.327-328. https://doi.org/10.1111/ceo.13309.

Persistent Link:

http://hdl.handle.net/11343/284071 